\title{
Implementation of the Brazilian National Network for Practices and Research with Progress Testing - BRAZ-NPT
}

\author{
Implantação da Rede Nacional de Práticas e Pesquisa com o \\ Teste de Progresso - RNTP
}

\author{
Pedro Tadao Hamamoto Filho ${ }^{I}(\mathbb{D}$ \\ Angélica Maria Bicudo ${ }^{I I}$ iD
}

Dear Editor,

It is a pleasure to announce and share with the Brazilian medical education community that we have been awarded the American National Board of Medical Examiners (NBME) Latin America Grants Program. This grant will support the implementation of the Brazilian National Network for Practices and Research with Progress Testing (Braz-NPT) [Rede Nacional de Práticas e Pesquisa com o Teste de Progresso].

The NBME Latin America Grants Program aims to enhance the quality of evaluation in health professions in Latin America. Proposals should be designed to have a broad, sustainable impact in a specific region by building up local capacity for evaluating key learning outcomes and improving program quality at participating schools.

The project will be conducted by our institutions in partnership with the Brazilian Association of Medical Education (ABEM), in continuation with the ABEM's initiatives to disseminate the use of progress testing in all Brazilian medical schools. ${ }^{2}$ Today, there are 13 consortia in the country, following ABEM's regional offices. However, some of these consortia have few participating schools, and, due to the increase in the number of medical schools in Brazil, several medical schools do not use progress testing. Thus, they fail to utilize the excellent feedback opportunities provided by this assessment tool.

Therefore, the implementation of the Braz-NPT has five main objectives: 1) increase the number of Brazilian schools that adopt progress testing in their student assessment routines; 2) support the creation of new consortia of schools to conduct progress testing; 3) strengthen the currently weak consortia that have few participating schools; 4) strengthen the ABEM's regional offices to be responsible for the capillarization of information obtained by the Braz-NPT; and 5) encourage participating consortia to establish scientific research goals according to their needs and specifications.

To accomplish these objectives, this year a unified national exam will be given to all students from schools affiliated with existing consortia. Subsequently, several meetings will take place to support data analysis in collaboration with the participating schools. In the following year, workshops will be conducted to provide faculty development on writing good assessment items and the adoption of best practices for student assessment.

The NBME intends to not only fund meetings and workshops but also identify experts to join the meetings and help with faculty development activities. The ABEM will be responsible for centralizing communication with the schools and consortia and managing the national exam, including its creation and analysis of the results.

We hope that the implementation of the Braz-NPT will increase the exchange of experiences among schools throughout the country regarding the information provided by the routine use of progress testing. In addition, the periodic application of national exams may provide consistent data regarding the knowledge acquisition dynamics of Brazilian medical students. Furthermore, we hope that this network will encourage schools to perform scientific investigations with progress testing, leading to publications in prominent journals in our field.

Finally, we would like to thank the NBME for its confidence in our proposal. We will do our best to honor this grant. We would like to thank the ABEM and its current administrative council for supporting us in this proposal. In fact, the network was born within the association, and we strongly believe that the ABEM's participation in the proposal was very important (or even decisive) for this award granting. 


\section{REFERENCES}

1. National Board of Medical Examiners. Latin America Grants Program: Call for Proposals. Available at: <https://www.nbme.org/sites/default/ files/2020-01/Call_For_Proposals.pdf> Accessed on Mar 21, 2020.

2. Bicudo AM, Hamamoto Filho PT, Abbade JF, Haffner MLMB, Maffei CML. Consortia of cross-institutional progress testing for all medical schools in Brazil. Rev. bras. educ. med. 2019; 43(4):151-156.

\section{AUTHORS' CONTRIBUTIONS}

PTHF is the leader of the NBME project and wrote the dratf of this letter. AMB is the leader of Progress Test project in ABEM and revised this letter.

\section{CONFLICTS OF INTEREST}

None to be declared.

\section{CORRESPONDENCE ADDRESS}

Pedro Tadao Hamamoto Filho

UNESP - campus de Botucatu. Distrito de Rubião Jr, s/n. Botucatu/SP, Brasil

Departamento de Neurologia, Psicologia e Psiquiatria

E-mail: pedro.hamamoto@unesp.br 